\title{
Embedding the developmental approach in social work education and practice to overcome poverty: The case of Southern Africa
}

\author{
Tatenda G. Nhapi ${ }^{1,2}$ and Jotham Dhemba ${ }^{3}$
}

1 College of Health and Social Science, University of Lincoln, Lincoln, UK

2 Erasmus Mundus MA Advanced Development in Social Work

3 Department of Sociology and Social Work, University of Eswatini, Kwaluseni, Eswatini

Received 30 March 2020

Accepted for publication 23 May 2020

Published 30 June 2020

\begin{abstract}
This article examines the extent to which social work education and practice in Eswatini, Lesotho and Zimbabwe have embedded the developmental approach to address poverty and to bring about socio-economic transformation. This is particularly significant as social work has gained traction internationally as a problem-solving profession. However, it is argued that that there is a lack of clarity conceptually about how the developmental approach should be operationalised in order to deal with social issues afflicting African countries in general and Southern Africa in particular. Furthermore, the article examines challenges in the implementation of the developmental approach in economically fragile contexts such as Eswatini, Lesotho and Zimbabwe. The gaps and constraints in mainstreaming developmental social work are also examined in the context of poverty, globalisation and impacts of natural disasters. Challenges experienced by frontline social workers in mobilising communities through the application of a repertoire of developmental social work approaches have also received attention. The article is based on personal experiences of the authors in teaching and practicing social work in the three countries and this is complemented by reviews and analysis of research studies and policy documents and reports on the mitigation of poverty and the developmental approach. Importantly, pathways are offered by article to bolster embedding of developmental approach in social work education and practice. These pathways contribute to advancement Sustainable Development Goals (SDGs) especially the goal relating to the eradication poverty.
\end{abstract}

Keywords: elderly; poverty; youth; social protection; developmental social work

\section{Introduction}

The developmental approach has of late gained traction in social work education and practice in Southern Africa. This paradigm shift from welfare must be acknowledged within the wider context of current socio-economic challenges facing southern African countries and Africa as a whole. As such, mainstreaming the developmental approach to social work education and practice has become an imperative and requiring more than lip service. The continued over-reliance on remedial interventions has proved to be ineffective in addressing poverty and hunger, unemployment and preventable diseases problems bedevilling southern African countries. The unrelenting HIV and AIDS pandemic has also devastated the social fabric of these countries thereby exposing older persons, women, children, youths and people with disabilities to further vulnerability and social exclusion. Therefore, given that poverty reduction and its eventual eradication is the sine qua non of social work practice, the adoption of the developmental approach is imperative if the agenda for sustainable development is to be realised. Again, advancing the transformational poverty eradication agenda is advocated for in this article. Learned helplessness is slowly breeding across Southern African communities given overreliance on government handouts and donor agencies project 
management cycle grounded programmes. Overcoming poverty will need galvanising inert transformational capacities in communities as expounded in key tenets of developmental social work approaches through harnessing enduring social work methods of interventions as community development and group work.

It should, however, also be noted that economically and ecologically fragile communities experience less access to essential resources such as forests, minerals, food and water. As such, the logic of 'neoliberal capitalism', which precludes equitable resource sharing, has failed both the people and the planet (Shajahan and Sharma, 2018), thereby making it difficult for poor countries to escape from poverty. As noted by UN Environment (2018), given its geographical position and vulnerability, as well as limited adaptive capacity exacerbated by widespread poverty, no continent will be as severely affected by climate change as Africa.

To contextualise this assertion, the UN World Food Programme noted that 9.2 million people in southern Africa were 'acutely food insecure,' and that in the lean period up to March 2020 this number could rise to more than 12 million. In this regard the UN agency planned to assist approximately 5.4 million people with life-saving assistance and critical livelihood interventions in Zimbabwe, Mozambique, Lesotho, Eswatini (formerly Swaziland), Namibia, Madagascar, and Malawi (Tsiko, 2019). Also, the diminishing capacity to engage in sufficiently paid productive work and/or self-care also makes older persons in southern African countries vulnerable (Aboderin and Ferreira, 2008). Furthermore, family-based support systems for child protection, youth's empowerment and older persons' dignity enhancement, have been strained and rendered ineffective. Rapid socio-cultural changes, economic stress, rural to urban migration of the young and able bodied and the HIV/AIDS epidemics are arguably some of the key drivers for this state of affairs.

It is against this backdrop that the SDGs adoption by the United Nations General Assembly represents a call for the developmental approach to address the scourge of Global South poverty and underdevelopment. Therefore, whereas general economic growth is believed by modernisation theorists as solving social problems, the developmental approach emphasises linkages of economic and social aspects of development and the sustenance of the natural environment, including many elements of direct relevance to social work policy and practice (Jones and Truell, 2012).

\section{The main tenets of the developmental approach}

In this subsection the underpinnings of the developmental approach in social work are outlined. The strengths of the developmental approach are in its emphasis on macro interventions (resource poor countries) focusing on the entire population and the mobilisation of community resources to bring about sustainable development for all. The concept of development, according to Midgely (2013), has a dynamic connotation and refers to a process of change, growth, progress or evolution.

On the same note, Dziro (2013) outlines the mainstreaming of the developmental approach as encompassing:

- Capacity building, self-reliance opportunities and service users' involvement in planning productive employment;

- Self-employment and self-reliance as an outcome.

Also, within rapidly changing societies of the so-called Global South, the developmental approach emphasises certain traditional values and norms preservation for social and cultural breakdown prevention (Rwomire, 2011). This is argued by Rwomire as overcoming related chaotic situations of normlessness, lack of self-identification and the absence of a sense of belonging. In the same vein Mhiribidi (2010) asserted that the developmental approach to social welfare adoption intention is to discourage dependency and to promote service users' active and productive involvement in their own development. The developmental approach is therefore a strategy emphasising and promoting welfare and economic development linkages in endeavours to eliminate pervasive poverty which is a major problem on the African continent.

Furthermore, social development (developmental approach), social change, social justice, empowerment and liberation are key pillars of the social work profession (Mtetwa, 2016). More importantly, the grounding of these strategies and principles of human rights reinforce the social work profession's belief in the worth and dignity of all human beings and their inherent capacity for purposeful change. The adoption of the developmental approach therefore makes people more self-conscious and aware of their rights as well as making people self-reliant. Therefore, unlike curative or remedial social work the developmental approach makes people self-reliant (Gray, 2002). Furthermore, people's participation in issues affecting their welfare effectively minimises corruption and poor governance as there is a strong correlation between good governance and positive social development outcomes (Chitereka, 2009).

This article is set in a context where Global South social work is at the crossroads given its inappropriateness in addressing the socioeconomic challenges hence the need to shed off the welfare orientation inherited from its colonial past. It is therefore imperative to ditch the subtle vestiges of colonisation still embedded in social work theory and practice in Eswatini, Lesotho and Zimbabwe in order to deal holistically overcome poverty and social exclusion challenges. This therefore requires a paradigm shift from the remedial to a developmental focus in social work services provision. The social work curriculum needs to be recast to equip students and practitioners with the requisite knowledge and skills to address problems of poverty and to strengthen 
the capacities of service users to harness local resources and indigenous knowledge systems for their own betterment.

In this vein, this article provides an examination of the current socioeconomic situation and the state and dynamics of social work education and practice in Eswatini, Lesotho and Zimbabwe. It also explores prospects and challenges of social work education and practice as well as suggesting pathways guaranteeing desired outcomes for these countries. The suggested pathways underscore livelihoods security and enhanced social functioning mediated by a pro developmental approach to social work practice.

\section{Social work and poverty alleviation in Eswatini}

The Kingdom of Eswatini is a landlocked southern African country sharing borders with Mozambique to the east and South Africa to the north, south and west. Eswatini has a population of just over 1 million people, $48 \%$ of which are children, while it occupies a total landmass of approximately 17,000 square kilometres, making it the second smallest country in Africa. It is a middle-income economy ruled by a Constitutional Monarchy with a public administration defined by the Tinkhundla system of governance (Ministry of Sports, Culture, and Youth Affairs, 2015). Tinkhundla are local government institutions and presently there are 55 Tinkhundla centres in the country. Section 218 sub-section 2 of the Constitution of Eswatini, defines the primary purpose of the Inkhundla as that of decentralising services to bring them closer to the people and to enable them to take charge of their own development.

Eswatini is faced with a host of social problems including poverty as statistics from the Swaziland Households Income and Expenditure Survey (SHIES) of 2012 showed that $63 \%$ of the population lives below the poverty line of US\$2 a day. This state of affairs is also reflected in the results of the Multiple Indicator Cluster Survey (MICS) in 2010 showing that $70 \%$ of children live below the poverty line and that $80 \%$ of orphans and vulnerable children were living in poverty. Eswatini is also experiencing slow economic growth and high levels of unemployment especially among the youth. The country has also been impacted greatly by an unrelenting HIV pandemic with a prevalence, among the population aged between 15 and 49 years, of $27 \%$ in 2015, the highest recorded in the world (UNAIDS, 2016). What is concerning is that this is supposed to be the most productive population and an asset in the development process and the fight against poverty. Poverty in Eswatini is further worsened by the fact that the country has been experiencing periodic drought, when approximately $77 \%$ of its population depends on rain-fed subsistence farming for their livelihoods. Unemployment is also of grave concern especially among the youth as they represent the most significant share, of the population of Eswatini. As it stands close to 4 out of 5 Swazis are younger than 35 years (Ministry of Sports, Culture, and Youth Affairs, 2015) and therefore with the prevailing high levels of unemployment young people are deprived of opportunities to realise their potential and meet basic needs.

Consequently, due to the pervasiveness of poverty and the HIV/AIDS pandemic, among other factors, there was a drop in life expectancy from 60 years in 1997 to 32 years in 2004 and it then climbed up to 59 years (WHO, 2018) as a result of the widespread provision of life prolonging antiretroviral treatment (ART) in the country. The pervasiveness of HIV and AIDS in Eswatini presents a challenging context for attaining the desired outcomes of mainstreaming the developmental approach to address social problems. Poverty in Eswatini is also intractable owing to sluggish economic growth and the existence of social protection measures that are rudimentary and fragmented.

Social work education and training in Eswatini is offered at the University of Eswatini and at Eswatini Medical Christian University. It was introduced in the country in 2014 and is therefore relatively new given that it was about seventy-seven years after one of the first schools of social work in Africa; namely the Cairo School of Social Work in Egypt was established in 1937. One of the social work education objectives, at the University of Eswatini, is to prepare graduates competent in developing and implementing programmes, projects and social policies reducing poverty and meeting vulnerable peoples' needs (Social Work Task Team, 2017). The social work curriculum offers social development (developmental approach) as one of the courses, preparing students for developmental roles in their work. Additionally, University of Eswatini has a critical mass of courses reinforcing their developmental social work orientation. Some of these courses taken by students include human rights and social development, social policy and programme analysis, child welfare legislation, policy and practice, and gerontology among others. The curriculum at the University of Eswatini is, in other words, allencompassing, in order to equip graduates with the requisite knowledge and skills to address Eswatini's social problems and undertake developmental roles, including poverty alleviation.

Not many organisations employ social workers including those involved in developmental activities such as poverty alleviation. This presents challenges as students are not always able to secure placements in relevant agencies owing to the shortage of qualified supervisors. Also, what compounds the Eswatini social work training and fieldwork challenge is that some suitable agencies for students' placements do not employ social workers. Qualified social workers at a fieldwork agency enables field education training and mentoring to students. Again, there is a shortage of agencies that developmental social work is used and where students can undergo their fieldwork placement and get exposure to conceptual and practical underpinnings of implementing developmental social work approaches.

In this vein social workers employment pattern in Eswatini is opaque and empirical research initiation can have outcomes of establishing the state of affairs concerning social 
workers' utilisation. The few qualified Eswatini social workers are employed in His Majesty's Correctional Services (HMCS), child protection and none state welfare services organisations such as Bulembu, Carbrine Ministries, SOS children's homes and Vulamasango. Significantly, the Eswatini Department of Social Welfare employs social workers in pursuing its mandate for holistic welfare provision of Swazis however its modus operandi remains welfare oriented even though its functions should include poverty eradication. The Department operates a public assistance programme constituted by Public Assistance Grant (PAG) and the Old Age Grant (OAG). Even though PAG's objective is poverty alleviation among the poor and vulnerable Swazis, PAG applicants undergo rigorous meanstesting process resultantly a negligible number benefit from the programme. Albeit the intentions, the benefits for the lucky few who manage to qualify are very low which discourages even the poorest of the poor from applying for assistance. Similarly, the year 2005 introduced OAG in response to the rising tide of social problems resulting from HIV/AIDS, food insecurity caused by chronic drought conditions is also meant to cushion older persons against poverty. The old age pension is only E400 a month thus below the United Nations official poverty line of US $\$ 2.50$ a day thus insignificant impact on poverty among recipients.

The implementation of poverty alleviation measures often lacks exit strategies for reduced state assistance dependency of the poor. Simultaneously, notwithstanding public assistance programme inadequacy, the Eswatini Department of Social Welfare is hamstrung to address poverty challenges as it cannot be expected to meet even the most basic of the needs of recipients. In this regard, the Department of Social Welfare employs social workers to support service users, on the one hand, but the lack of resources makes for limited effectiveness given pervasive poverty. Thus, tailor made community level interventions may be more effective.

The Department of Social Welfare operations need transformation to enable social workers to harness the developmental approach in their practice. In line with the dictates of the developmental approach, Department of Social Welfare social workers should empower public assistance and old age grants recipients to become self-reliant by using their income to engage in self-help and incomegenerating projects individually and also in groups. It would also be necessary for social workers in Eswatini to shift from focusing on individuals to interventions that promote community development which has potential to improve the quality of life of the population altogether.

\section{Social work and poverty alleviation in Lesotho}

Unlike the Kingdom of Eswatini, which is partially surrounded by South Africa, Lesotho, as some analysts would say, is located in the "belly" of South Africa because it is completely encircled by that country. Geographically, Lesotho is of a relatively small size occupying a land area of about 30,000 square kilometres which arguably makes it one of the smallest countries in the southern hemisphere. Lesotho is also a mountainous country with $80 \%$ of the land being mountains and less than $20 \%$ of this land is arable which limits its agricultural potential. Its population is, however, relatively small when compared to other African countries as it is approximately 2 million (Bureau of Statics Lesotho, 2007).

Nonetheless, in spite of its mountainous topography Lesotho is predominantly an agricultural economy. The majority of its population $(77 \%)$ reside in the mountainous rural areas where access to services is limited and socioeconomic infrastructure is generally underdeveloped. There are however three major sources of formal employment in the country, namely mining, government and the garment and textile industry (National AIDS Commission, 2010).

Poverty, unemployment which is about $45 \%$, high inequality, orphans and vulnerable children as well as HIV and AIDS are major problems facing the country. Lesotho's HIV/AIDS prevalence rate was estimated at $23.3 \%$, making it the third highest in the world (National AIDS Commission, 2010). Other Lesotho social problems include high drug and substance abuse incidence, child abuse, domestic violence, retrenchment of workers from South African mines and the effects of natural disasters (Manyeli, 2007).

The United Nations (2009) asserts that $40 \%$ of the population of Lesotho lives below the United Nations "official" poverty line of US $\$ 1.25$ per day. The high level of inequality in the country is also demonstrated by its Ginicoefficient which was estimated at 0.52 in 2003 (Bello et al., 2008).

Lesotho social work practice history as elsewhere in Africa is inextricably linked to the evolution of social welfare services during the colonial era. Its history can be traced to the establishment of the Department of Social Welfare (now Ministry of Social Development) under the then Ministry of Health in 1976 in response to the rising tide of social problems in the country (Dhemba and Marumo, 2017). These developments also prompted the introduction of a four-year Bachelor of Social Work programme at the National University of Lesotho in 2002 in an endeavour to respond to the many social problems bedevilling the country.

Lesotho's only social work degree awarding institution is the National University of Lesotho. However, the National Health College followed with the provision of social work training in Lesotho; by offering a two-year certificate in Auxiliary Social Work. The certificate in auxiliary social work was introduced to provide low level social work cadres who would work at the community level liaising with health and other social services and also as conduits between the community and district level services.

According to Tanga (2013), the National University of Lesotho's social work programme was based on the School of Social Work (Zimbabwe) model, which replicated Western value systems and models. However, like many 
other Global South universities there have also been curriculum indigenisation initiatives to be responsive to social problems in the country. To this end the social work curriculum includes a stand- alone course on social development. Social development is also infused or cuts across all the other courses in an attempt to promote social work interventions that address the developmental challenges facing the country.

Lesotho's Ministry of Social Development formerly the Department of Social Welfare is the major social workers employer which adopted the developmental approach upon its renaming in 2012/2013. This provided a major impetus to the transformation from a welfare orientation to a developmental focus in the provision of social welfare services in Lesotho. In this vein the National Policy on Social Development 2014/2015-2024/2025 emphasises the government's priorities as follows:

- combating poverty, deprivation and inequality, protection of older persons,

- $\quad$ protection of children, HIV and AIDS,

- $\quad$ promoting gender equality,

- disaster risk management,

- empowerment of youth, protection and rehabilitation of persons with disabilities,

- rehabilitation of offenders and ex-offenders, family preservation, and community development (Government of the Kingdom of Lesotho, 2014).

While these are laudable developmental goals, their pursuit is fraught with challenges. For example, although Lesotho spends $4.5 \%$ of its gross domestic product on the budget for social assistance, nearly tripling the average for sub-Saharan Africa (Kardan and O'Brien, 2017) the country is facing high and rising levels of poverty. The old age pension programme which was introduced in 2004 and is one of the social protection measures to address poverty in old age provides for a monthly pension of M550. This, however, is not enough to meet the needs of older persons let alone to propel them into self-sufficiency.

Additionally, the public assistance programme by the Ministry of Social Development aims at addressing poverty challenges but it is exclusionary and therefore benefitting a few people. This is mainly because of means-testing in circumstances where the majority of people are poor thus a few people benefit from this programme. Furthermore, the public assistance allowance is only M250, thus inadequate for transformational poverty eradication. The public assistance programme's effectiveness is also compromised by the lack of transformation from welfare to a developmental focus. Social workers employed at the Ministry of Social Development continue to provide welfare assistance as an end in itself and not as a means to an end. The method of intervention remains largely casework, which is of limited effectiveness in addressing issues of poverty as the focus is mainly on individual pathology.
There is however hope that with Lesotho's Ministry of Social Development restructuring into a number of departments including Childcare services, Elderly care services, Disability services and Community Development (Dhemba and Marumo, 2017) more impetus will be to provide more professional and effective interventions. As an example, it is envisaged that the Department of Community Development will mobilise and organise recipients of public assistance and old age pension to form mutual aid and income generating groups to promote self-reliance. This will help to improve their wellbeing and quality of life.

A noteworthy challenge is that the Lesotho's Ministry of Social Development budgetary allocation is perennially inadequate to the extent that developmental social work programme implementation is difficult; such programmes require robust financial support. Furthermore, whereas social workers should engage in outreach community work instead of waiting for service users to come to their offices transport and other financial resources, shortages hinder developmental approach implementation that could target bolstering for example service users' initiated income generation projects.

\section{Social work and poverty alleviation in Zimbabwe}

Ranked 154th (out of 187 countries) in the 2016 Human Development Index, with a GDP of 17.85 billion USD (2017) and an estimated population of about 16.3 million, Zimbabwe is classified as a low-income country (United Nations Development Programme UNDP, 2018). Economic challenges the country has experienced include a high unemployment rate of more than $90 \%$, cash liquidity challenges and eroded livelihood options. Unlike people in rural areas, the urban population relies on formal and nonformal employment for their livelihoods as agriculture is not a sustainable source of livelihoods in urban areas. The ongoing cash liquidity problems, industries' closure, low foreign investment and low salaries make most households highly vulnerable with limited basic social services access (United Nations Development Programme UNDP, 2018).

Two socio-economic blueprints underpin Zimbabwe's socio-economic development agenda for the country's socioeconomic transformation. These are namely the Transitional Stability Programme and the 2016 Interim Poverty Reduction Strategy. In terms of Zimbabwe's economic trajectory, International Monetary Fund (IMF) (2019) noted difficulties have continued throughout 2019, exacerbated by severe weather shocks. GDP growth in 2020 is expected to be steeply negative given drought effects on agricultural production and electricity generation, cyclone Idai impact, and the significant fiscal consolidation to correct past excesses serve to drag on growth. Social conditions have deteriorated sharply, with more than half of Zimbabwe's population ( 8.5 million people) estimated by the UN to be food insecure in 2019/2020. In 2019, tropical cyclone Idai brought late season rainfall to the eastern parts of the country, mainly Chimanimani and Chipinge districts, though 
this rainfall led to severe flooding, destroyed crops and infrastructure and disrupted livelihoods (Famine Early Warning Network, 2019). Natural disasters frequency of such as droughts and seasonal floods in the past few years have threatened agriculture, food and nutrition security and the environment (Food and Agriculture Organisation, 2017). Moreover, as outlined by Scoones Zimbabwe's land reform of 2000 resulted in an unprecedented restructuring of the agrarian system, with a massive transfer of land to a mix of smallholder and medium-scale farmers.

Gondo (2019) comments that young people's growing marginalisation in Zimbabwe is not only political, but structural in that the political mentality stipulates youth are the leaders of tomorrow continue to shrink the youth space. Significantly, Zimbabwe's youth development space is epitomised by basic rights violations, that is lack of decent jobs, exorbitant education, limited health care access, drug abuse, lack of civic space to innovate and participate (Gondo, 2019).

Finally, Zimbabwe social work training is fairly sophisticated with four institutions offering Bachelor of Science Social Work Honours qualification training. A vibrant National Association of Social Workers Zimbabwe grouping is also in existence and has been largely visible in advancing the developmental social work agenda. Moreover, strong social work professional ethical standards are enforced by the Council of Social Workers Zimbabwe which is also responsible for registering and regulating social workers. However, as mentioned elsewhere in this article socio-economic turbulence has been threatening vibrancy of social work training and practice lately. Seasoned social work academics have started migrating into the region and this may have a likely impact of less robust social work approaches training. This trend has not yet fully manifested itself. Again, experienced social workers who have benefitted from training and capacity building to be proactive proponents of developmental social work are migrating yet again to the so-called 'greener pastures' in UK and Australia. This staff attrition principally in the Department of Social Services reverses the gains recorded in advancing the developmental social work agenda that Zimbabwe was poised to attain.

\section{Discussion}

Drawing on the previous accounts on the Kingdom of Eswatini, Lesotho and Zimbabwe, this section explores the dominant narratives that have impeded robust developmental social work mainstreaming in these regions.

\subsection{Unemployment}

Unemployment in Zimbabwe is also impacting graduate social workers (Dziro, 2013). Dziro observed this affects social work's transformational approach toward social development through fighting unemployment, underemployment and poverty. Undeniably, there is failure to retain social workers. The Department of Social Services, for example, suffered consistent staff attrition in 2018, with large numbers of previously trained and experienced staff moving mainly to the United Kingdom and Australia (UNICEF, 2018). In Lesotho, the expectation is for the poor, people with disability and OVC to get social protection but one cannot turn a blind eye to the structurally unemployed workers who also need the same support (Manyeli, 2007). To alleviate non availability of social security on service users, social insurance plays a pivotal role in preventing poverty (Kaseke, 2013). It is thus an anti-poverty form of social security preventing insured individuals from sliding into poverty in the event of being exposed to a social risk. In Lesotho, as Manyeli (2007) observes, the semi- formal social security schemes have also proven to be stronger mechanisms for poverty alleviation and prevention. These practices have held participatory approach whereby people were being assisted to help themselves just as it is encouraged in the profession of social work. Therefore, developmental social work interventions in Lesotho, Eswatini and Zimbabwe must emphasise practice research for a solid empirically informed practice.

Unemployment remains pervasive in Lesotho, Eswatini and Zimbabwe. Overcoming this social challenge requires innovative programmes to augment various income generating projects focused interventions implemented by state and non-state actors. However, one key social work tenet of service user self-determination needs to guide design and implementation of programmes to overcome unemployment. Imposing conditional cash transfers to service user categories as youths may be deemed as stigmatising. This is because it may be interpreted by youths as being condemnation to being state and none state handouts recipients for lack of imaginative ideas. Therefore, offering a platform to bolster entrepreneurial capacities through incubator schemes is one-way developmental social work may manifest in overcoming unemployment.

\subsection{HIV and AIDS}

HIV and AIDS mitigation interventions can be noted as platforms to innovate and embed developmental social work. This is illumined by Gregson et. al (2013)'s study in Zimbabwe, which notes that although all the community groups investigated by the study were established with a specific purpose to respond to the HIV epidemic, most of the groups provided support to people affected by HIV in indirect ways. For example, the farmers' association provided members with the skills to farm as well as access to farming implements from NGOs, opening up opportunities for income generation in a community where poverty has dramatically exacerbated the impacts of AIDS. The burial society provided its members with the insurance of burial support following the bereavement of self or a close family member. However, common across all the FGDs was recognition that participation in community groups provides a safety net for people living in low resource and high HIV prevalence communities. 
Since Zimbabwe, Lesotho and Eswatini all grapple with HIV and AIDS impacts, galvanising Person Living with HIV and AIDS (PLWHAs) through harnessing the developmental social work paradigm will contribute to social and economic well-being outcomes of PLWHAs.

PLWHA groupings should be supported through social work interventions so that government and other duty bearers conform to commitments as the African Union's year 2001 Abuja Declaration on Health Funding. This declaration stipulates that African governments dedicate 15 percent of their national budgets to health funding. We argue that through social workers' involvement with PLWHAs in advocacy, duty bearers as ministries of health, finance will reflect on their obligations is guaranteeing accessible to affordable and holistic health. In this regard the desired outcomes will be annual budgetary allocation reviews for them to be more pro PLWHAs with lesser reliance on HIV and AIDS programming donor funding.

This can be achieved through embedding developmental social work approaches which can entail collaboration between social workers and community groupings representing PLWHAs. This can be at platforms as annual budget consultations meetings, World Health Day, World AIDS day commemorations.

\subsection{Empowering service users}

Lombard (2015) argued that a clearer grasp by social workers, of how they think society operates, assists them to gain a fuller understanding of the origin of service users' problems and their lived experiences. Cirillo and Tebaldi, (2016)'s survey of non-contributory social protection programmes across Africa found that $40 \%$ of programmes are implemented with the financial or technical support of external agencies or NGOs. Again, this article notes Mtetwa (2016)'s comments that advancing theories as conservatism, liberalism and human rights theories necessity in social work's dramatic shift from a highly philanthropic, remedial and charitable approach towards a more rights-based political and economic orientation. When social work is more oriented towards politics and economics duty bears with obligations like advancing citizens socio-economic rights, are better held to account. This can include instances where natural resources are extracted without benefits cascading to grassroots communities. The three countries of Lesotho, Zimbabwe and Eswatini have varying degrees of natural resources ranging from agricultural land, water and minerals.

UNICEF notes Lesotho's public services provision to children and their families including community people, particularly those based in remote villages as the service user empowerment challenge. The Government of Lesotho has a Decentralisation Policy and Community Council structures have been established. However, Unicef (n.d) notes ministries have not devolved functions that can support delivery of services for children, their families and rest of the community. Secondly lack of fiscal decentralisation has also impacted on limited services that can be offered by the community councils.

However, there is little evidence that indicates safety net programs are not particularly well targeted to the poorest; empirical evidence that recognise best methods in the Eswatini context. In Lesotho, Manyeli (2007) points out that semi- formal social security schemes have also proven to be stronger mechanisms for poverty alleviation and prevention. These practices have held participatory approach whereby people were being assisted to help themselves just as it is encouraged in the profession of social work. Therefore, developmental social work interventions in Lesotho, Eswatini and Zimbabwe must emphasise on empirically informed practice.

\subsection{Climate change and livelihoods security}

As pointed out elsewhere, evidence about climate change impacts on marginalised people and awareness about the interrelationships between humans and the biosphere are antecedents compelling social workers to act environmentally (Shajahan and Sharma, 2018). In Zimbabwe, Mathende and Nhapi (2016) note sustainable environmental management and protection issues have always dominated the research agenda of some researchers and development practitioners. An estimated population of 1.1 million rural Zimbabwean households live in communal areas in a land area of 16.4 million hectares and policymakers need to understand the constraints, challenges and opportunities of rural settings (Scoones, 2019). Climate shocks - particularly drought and floods - are common and increasingly in frequency. The government declared a state of drought emergency on 22 December 2015. The shock is set against a backdrop whereby, even though Lesotho is now a lower middle-income country, $57 \%$ of the population is thought to be below the poverty line (Kardan and O'Brien, 2017).

Given this climate change and livelihoods security context, Kang'ethe (2014) asserts that versatility of social workers training makes them direct their practice efforts in the area of food security. According to the same author, since most African economies are agro-based, incorporating some agriculture-based courses in social work curriculum could enhance social workers' capacity to offer hands-on advice. However, Mathende and Nhapi (2016) caution social workers representative bodies as the Council of Social Workers and the National Association of Social Workers Zimbabwe, which can then harness synergies and promote such structures. Important commemorations on the UN calendar as World Wetlands Day, World Environment Day, World Consumer Day, Zimbabwe's own National Tree Planting Day, and World Social Workers Day can be vehicles to engage in advocacy activities through collaboration in development work structures to plant trees, engage in clean up campaigns whilst advocating for environmental justice. 
However, Mathende and Nhapi (2016) argue that donor driven programming can be challenging, in an attempt to initiate such kind of approaches. Any engagement of environmental management actors concerned to cascade key resolutions to the grassroots is successful until donor funds in programming cycle dry up (Mathende and Nhapi, 2016). For Zimbabwe, we argue that it is disconcerting that in the aftermath of the devastating March 2019 cyclone, the National Association of Social Workers Zimbabwe (NASWZ) was not proactive and did not despatch members nor sustain a visibility campaign showcasing professional social workers as being in solidarity with those affected by the extreme weather events.

\subsection{Ageing population}

Pertinently, enhancing dignity and social functioning of the elderly should always be one of the premises on which developmental social work embedding should be hinged on. Firstly, in the case of Eswatini, analysis of its largest cash transfer program the Old Age Grants (OAG) indicates potential positive impacts in mitigating the elderly's poverty. OAG was introduced in 2005 to cushion the elderly from impacts of loss of support due to the deaths of their adult children and burden of caring for orphaned grandchildren. Qualitative evidence suggests that the OAG has had a positive impact on beneficiaries lives but has not contributed much in terms of reducing poverty because a significant share of $\mathrm{OAG}$ resources go to non-poor households. Moreover, Ansell et al.'s (2019) study in Lesotho demonstrates cash transfers benefits for older people, their families and communities. Their rural Lesotho and Malawi research showed that the elderly are not the only ones to benefit from these schemes; they also have a positive knock-on effect on families and communities. Ansell et al. (2019) found that cash makes older people better off materially, but also less reliant on others and, in some cases, older people were able to exercise decision-making power around household purchases or investments. This was notable in Lesotho, where the transfer amounts are greater. For example, older people no longer needed to keep asking their grandchildren to collect water but could offer them money or pay a neighbour to do so instead. Dhemba (2012) argues that means-testing exclusion of those aged 60 to 64 years makes Zimbabwe's Older Persons Act inadequate to guarantee social and economic security in old age.

\subsection{Youth bulge}

If developmental social work is to be realised in Southern Africa, youth development must be one of the scheme's pillars. Scoones et al. (2019) assert international and regional policy commentary reflects local media and policy discussion, offering both positive and negative narratives about the role of youth. For some, youth are seen as a threat to stability: unemployed, footloose and prone to disruptive, political activism. Resultantly, young people may be cast as dangerous and in need of controlling (Scoones et al., 2019).
In many policy debates, Scoones et al. (2019) opine that youths are identified as either a potentially socially disruptive threat or as entrepreneurial initiators of a new economy. Eswatini's State of the Youth Report underscores the need to understand Eswatini population dynamics as critical underpinning for any discussion surrounding the future of the Kingdom's youth and harnessing the potential demographic dividend in the country (The Ministry of Sports, Culture, and Youth Affairs, 2015).

Ansell et al. (2019) conducted a Lesotho and Malawi study aiming at investigating young people's own views about how policy might best help to improve their lives. They examined ways in which three cash transfer schemes are designed, operate and affect rural lives: Lesotho's Old Age Pension, Child Grants Programme as well as Malawi's Social Cash Transfer Programme. Qualitative research was undertaken in two rural communities, one in the sparsely populated Maluti Mountains of Lesotho and the other in densely populated Thyolo District in southern Malawi. The study noted that young people prefer that cash transfers are not given as 'free money' because of the shameful association that they are unable or unwilling to work. Young people aspire to having good jobs, and state that they want to work for money, but work is often unavailable or involves exploitative conditions. Entrepreneurial capacities incubation for the youths in the three Southern African countries should be backed up by requisite safety nets. As most youths' involvement in Income Generation Projects does not guarantee their access of formal social security channels, informal social security must be guaranteed. Furthermore, application of a developmental social work grounded youth intervention should support youth greater involvement in issues of concern to them like overcoming socio-pathological vices of drug abuse, prostitution and violence at behest of politicians. As it stands not only livelihoods security interventions can sensitise youths against the urges of "vice and wheeling dealing' in contexts or pervasive unemployment.

\section{Conclusions}

Though Lombard (2015) asserts that social workers and social development practitioners are in the frontline to alleviate the hardships and challenges that people, communities and societies face, it is evident from the foregoing that without economic and social support from the state and non-state actors and communities, empowerment through developmental social work will be an unfinished project. This paper therefore suggests a number of pathways for the adoption and implementation of the developmental approach. Firstly, national and regional social work groupings like the Association of South African Social Work Education Institutions (ASASWEI) and Southern African Social Policy Experts Network (SASPEN) should be structured to serve as regional hubs to serve as developmental social work dissemination platforms. In this way they serve as spaces for the mutually beneficial exchange of data, information and knowledge. 
Secondly, developmental social work knowledge management and knowledge procreation can be enriched through establishment of regionally focused master Programmes. This can expedite the benchmarking of developmental social work within Eswatini, Lesotho and Zimbabwe and beyond. Academics, funds and political will permitting in these countries, the establishment of a regional master study modelled on the European Erasmus Mundus MA Advanced Development in Social Work programme could be established. The Graduate, Erasmus Mundus MA Advanced Development in Social Work is a joint Programme involving the University of Lincoln (England); Aalborg University (Denmark); Technical University of Lisbon (Portugal); University of Paris Ouest Nantere La Defense (France) and Warsaw University (Poland). It is through the professional deconstruction of silos that developmental social work outcomes can be enhanced. When professionals from other disciplines collaborate with social workers, drift in developmental social work outcomes is minimised. This is particularly important as some components of developmental social work may not be in the remit of social workers and gate keepers may include community leaders such as traditional chiefs and others

Finally, and probably more importantly social workers in Departments of Social Welfare and Ministries of Social Development should focus on interventions that promote community development as this has the potential to improve the quality of life of the population altogether. On the same note it is imperative for social workers to ensure the provision of adequate and comprehensive social protection for vulnerable populations not only as a fundamental basic human right but also to safeguard the material and mental wellbeing of vulnerable members of society.

\section{References}

Aboderin, I. and Ferreira, M. (2008) 'Linking Ageing to Development Agendas in Sub-Saharan Africa: Challenges and Approaches', Journal of Population Ageing, 1(1), pp. $51-73$

Ansell, N., van Blerk, L., Robson, E., Hajdu, F., Mwathunga, E., Hlabana, T. and Hemsteede, R. (2019) Social cash transfers, generational relations and youth poverty trajectories in rural Lesotho and Malawi. London, UK: Brunel University, available at www.cashtransfers-youth.net (accessed 12 January 2020)

Bello, H., Letete., M. Rapapa, N. P. and Chokobane, L. (2008) 'An evaluation of the poverty reduction impact of the non-contributory old age pension programme in Lesotho: The case of Manonyane community area'. Review of Southern African Studies Journal-ISAS, 12 (1\&2), pp. 76106.

Bureau of Statistics Lesotho (BOS) (2007) Lesotho 2006 census of population and housing preliminary report. Maseru,Lesotho: Government Printers.
Chitereka, C. (2009) 'Social Work Practice in a Developing Continent: The case of Africa', Advances in Social Work, 10(2), pp. 144-56.

Cirillo, C. and Tebaldi, R. (2016) Social Protection in Africa:An inventory of social protection programmes in Africa. International Policy Centre for Inclusive Growth/UNICEF, available at:,http://www.ipcundp.org/pub/eng/Social_Protection_in_Africa.pdf (Accessed 10 May 2018).

Dhemba , J. and Marumo, M. (2017) 'Social work practice in Lesotho's Ministry of Social Development' in Gray, M. (ed.) The Handbook of Social Work and Social Development in Africa. London, UK: Roulegde, pp. 49-58.

Dhemba, J. (2012) 'Dynamics of poverty in old age: the case of Zimbabwe', International Social Work, 57(6), pp. 714-22

Dziro, C. (2013) 'Trends in social work education and training: The case of Zimbabwe', International Journal of Development and Sustainability, 2(2), pp. 14-23.

Famine Early Warning Network (2019) Zimbabwe Food Security Outlook June 2019 to January 2020, Washington,USA: Famine Early Warning Systems Network.

Food and Agriculture Organisation (2017) National Gender Profile of Agriculture and Rural Livelihoods - Zimbabwe: Country Gender Assessment, Harare,Zimbabwe: FAO.

Gondo, M. (2019) Zimbabwe Youth Sector. Available at: http://citizensmanifesto.org/2019/09/19/zimbabwe-youth-sector/

(Accessed 20 September 2019).

Government of the Kingdom of Lesotho (2014) National Social Protection Strategy, Maseru,Lesotho: Government of the Kingdom of Lesotho.

Gray M. M. (2002) 'Editorial - Dancing to the beat of our own drum', Social Work / Maatskaplike Werk, 38(4), pp. 324-336

Gregson, S., Nyamukapa, C., Schumacher, C., MagutshwaZitha, S., Skovdal, M., Yekeye, M., Sherr, L. and Campbell, C. (2013) 'Evidence for a contribution of the community response to HIV decline in eastern Zimbabwe?', AIDS Care, 25(1), pp. 88-96.

Jones, D. and Truell, R. (2012) 'The Global Agenda for Social Work and Social Development: Aplace to link together and be effective in a globalized world', International Social Work, 55(4), pp. 454-72.

Kang'ethe, S. M. (2014) 'Exploring Social Work Gaps in Africa with Examples from South Africa and Botswana', Journal of Social Science, 41(3), pp. 423-31.

Kardan, A. and O'Brien, C. (2017) Building on social protection systems for effective disaster response: the Lesotho experience. Oxford, UK: Oxford Policy Management. 
Kaseke, E. (2013) Informal social security in southern africa.

Available

http://www.saspen.org/conferences/informal2013/Paper_Kas eke_FES-SASPEN-16SEP2013-INT-CONF-SP4IE.pdf (accessed 12 January 2020).

Lombard, A. (2015) 'Global Agenda for Social Work and Social Development: A path towards Sustainable Social Work', Social Work/Maatskaplike Werk, 51(4), pp 482-99.

Manyeli, T. (2007) 'The Evolution of Social Welfare in Lesotho', Lesotho Social Science Review, 11(1\&2), pp. 2132.

Mathende, T. and Nhapi, T. (2016) 'Social workers as environmental preservation vanguards: Zimbabwean professionals' potential change agent roles', African Journal of Social Work, 6(2), pp. 30-47.

Mhiribidi, S. T. (2010) 'Promoting the developmental social welfare approach in Zimbabwe: Challenges and prospects', Journal of Social Development in Africa, 25(2), pp. 123-46.

Midgley, J. (2013) The Theory and Practice of Developmental Social Work. Oxford: Oxford Press.

Ministry of Sports, Culture, and Youth Affairs (2015) State of the Youth Report, Mbambane, Eswatini: Government of Swaziland.

Mtetwa, E. (2016) 'Implementation of appropriate minimum body of knowledge in training and practice of social work in Zimbabwe', African Journal of Social Work, 6(1), pp. 42-50.

National AIDS Commission (2010) Lesotho UNGASS Country Report: Status of the National Response to the 2001 Declaration of Commitment on HIV/AIDS 2008-2009. Maseru, Lesotho:National AIDS Commission.

OCHA Regional Office for Southern and Eastern Africa (2019) Available at: https://reliefweb.int/sites/reliefweb.int/files/resources/Zimba bwe_Sitrep9_6June2019.pdf(Accessed 5 October 2019).

Rwomire, A. (2011) 'The Role of Social Work in National Development', Social work and society, 9(1), pp. 108-18

Scoones, I. (2019) Land and tenure in Zimbabwe's communal areas: why land reform was needed. Available at: https://zimbabweland.wordpress.com/

(Accessed 19 October 2019).

Scoones, I., Mavedzenge, B. and Murimbarimba, F. (2019) 'Land in Zimbabwe: livelihood challenges after land reform', Review of African Political Economy, 46(159), pp. 117-34.

Shajahan, P. and Sharma, P. (2018) 'Environmental justice: A call for action for social workers', International Social Work, 61(4), pp. 476-80.

Social Work Task Team (2017) Field education manual and policies. Kwaluseni, Eswatini: Department of Sociology and Social Work.
Tanga, P. T. (2013) 'Challenges of social work field training in Lesotho', Social Work Education-The International Journal, 32,(2), pp.157-78.

Tsiko, S. (2019) 9,2m in Southern Africa acutely food insecure: UN. Available at: https://www.herald.co.zw/92min-southern-africa-acutely-food-insecure-un/

(Accessed 26 September 2019).

UN Environment (2018) Responding to climate change. Available

https://www.unenvironment.org/regions/africa/regional-

initiatives/responding-climate-change (Accessed

at:

September 2019).

World Health Organization (2018) Child growth standards: length/height-for-age. Geneva: World Health Organization. Available

at: http://www.who.int/childgrowth/standards/height_for_age/en I. (accessed 21 January 2020).

World Health Organisation (2018) Swaziland country cooperation at a glance. available at: https://apps.who.int/iris/bitstream/handle/10665/136886/ccsb rief_swz_en.pdf; jsessionid=8854AD5E34818FD2A7A5EC3 0C3F7EC20? sequence $=1$ (Accessed 23 February 2020).

UNAIDS (2019) Eswatini. Available at: https://www.unaids.org/en/regionscountries/countries/swazil and (Accessed 12 July 2019).

UNICEF (2018) UNICEF Zimbabwe is inviting proposals from individual qualified national consultants for the Social Norms and Violence Against Children Prevention Systems Support Coordinator assignment. Available at: https://www.unicef.org/about/employ/?job=518755 (Accesed 12 Novemnber 2019).

UNDP (n.d.) UNICEF Lesotho Social Policy. Available at: https://www.undp.org/content/dam/unct/lesotho/docs/unicef/ Unicef_CP_FS_Social\%20Policy_FA_LR\%20(002).pdf (Accessed 20 May 2020).

United Nations Development Programme UNDP (2018) Comprehensive National Study on Urban Resilience and Developing Urban Resilience National Strategy in Zimbabwe. Available at: http://procurementnotices.undp.org/view_notice.cfm?notice_id=52146 (Accessed 5 April 2019). 